\title{
What It Takes to Be a Pioneer: Ability Expectations From Brain-Computer Interface Users
}

\author{
Johannes Kögel $(\mathbb{D})$ Gregor Wolbring $(\mathbb{D}$
}

Received: 8 April 2020 / Accepted: 18 October 2020 / Published online: 10 November 2020

(C) The Author(s) 2020

\begin{abstract}
Brain-computer interfaces (BCIs) are envisioned to enable new abilities of action. This potential can be fruitful in particular when it comes to restoring lost motion or communication abilities or to implementing new possibilities of action. However, BCIs do not come without presuppositions. Applying the concept of ability expectations to BCIs, a wide range of requirements on the side of the users becomes apparent. We examined these ability expectations by taking the example of therapeutic BCI users who got enrolled into BCI research studies due to particular physical conditions. Some of the expectations identified are quite explicit, like particular physical conditions and BCI "literacy". Other expectations are more implicit, such as motivation, a high level of concentration, pain tolerance, emotion control and resources. These expectations may produce a conception of the human and a selfunderstanding among BCI users that objectify the body in favour of a brain-centred, cerebral notion of the subject which also plays its part in upholding a normality regime.
\end{abstract}

\footnotetext{
J. Kögel $(\bowtie)$

Institute of Ethics, History and Theory of Medicine, Ludwig Maximilian University of Munich, Lessingstr. 2, 80336 Munich, Germany

e-mail: johannes.koegel@med.uni-muenchen.de

G. Wolbring

Community Health Sciences, Cumming School of Medicine, University of Calgary, 2500 University Drive NW, Calgary, AB T2N 1N4, Canada
}

Keywords Ability expectation · Brain-computer interface $\cdot$ Neuroscience $\cdot$ Disability studies . Disembodied mind $\cdot$ Normality regime

\section{Background}

The neurotechnology of brain-computer interfaces (BCIs) has established a fast growing and progressing field of research, attached with high hopes and great promises for potential end users as well as researchers. BCIs are systems that measure brain activity, convert them into computer commands and result in some artificial output [1]. The output consists of directing external devices such as personal computers, wheelchairs or prostheses, or activating a person's muscles [2-7]. For steering a BCI, no voluntary muscle movement is required. One basically operates the BCI simply by the power of one's thoughts. Applications of BCIs comprise medical training that aims to restore or increase communication and motor skills of persons with physical impairments, improve the neurological condition of persons that suffered stroke or spinal cord injuries, regulate epilepsy and treat psychiatric conditions [8-11].

Studies stressing the potential benefit of braincomputer interfaces for users, in particular persons with degenerative diseases and physical impairments, abound. Brain-computer interfaces can possibly bring about "restoration of agency and autonomy" [12] and "enhance self-determination" [13]. There is "need for autonomy and need for competence" among amyotrophic lateral sclerosis (ALS) patients, and BCIs are 
regarded as a technology that can possibly fulfil these needs [14]. In addition, BCIs are expected to improve the users' quality of life [15-21]. Studies with potential BCI users identified hopes such as improving autonomy [22], "autonomy and empowerment" [23], more independence in terms of mobility, daily life activities and employment [24], and communication opportunities $[25,26]$. In addition, there are non-medical applications of BCIs such as gaming, entertainment, and enhancement $[27,28]$.

Several studies pinpoint the weaknesses of current BCI applications, such as low speed and efficiency, discomfort, difficulty of use, fatigue and disappointment [29]. Accordingly, requests made by users included ease of use, higher efficiency, increased comfort, integration of various functions and the possibility for home use [29]. A recent qualitative interview study with therapeutic BCI users shows that BCI use can bring about various effects [30]. Some are more direct effects such as improving the users' physical condition or restoring lost body functions. Among the more indirect effects are opportunities for social participation, having a task at hand that contributes to science and technological progress and can bring about pride, self-esteem and social recognition as well as opportunities to maintain particular ways of self-recognition and self-description.

In contrast to what users expect and get out of using BCIs, it has not been examined what BCI use expects or presupposes from the users. As a big part of technology development is done for medical purposes and the BCIs thus engineered are meant to assist people with physical impairments, we shall put our focus on the expectations set towards the physically impaired BCI user. In that regard - taking a look at the academic literature on BCIs, a particular image of the disabled user of BCIs is portrayed. Wolbring and Diep [31] suggest that disabled people are depicted by means of a medical narrative and an ability-deficient language. Disability is associated with medical impairments or diseases and described as being "fatal" or "devastating". Disabled people are exclusively portrayed as therapeutic BCI users and not as non-medical BCI users [31].

For this article, we focused on therapeutic BCI users that had been enrolled in BCI studies due to particular physical conditions, mostly degenerative diseases or spinal cord injuries. To illustrate the ability expectations that therapeutic users see themselves confronted with when using a $\mathrm{BCI}$, we draw on some interviews which were conducted with participants of such BCI studies.
Given that BCIs are quite a recent technology and only few people have operated a BCI so far and hence feel like "pioneers" in that field, we pose the question what is required of $\mathrm{BCI}$ users to successfully operate a $\mathrm{BCI}$ : What does it take to be a "pioneer"?

For that purpose, we draw on the concept of ability expectations which will be explained and applied to BCIs. Drawing on the accounts of BCI users, we will identify explicit and implicit ability expectations that users see themselves confronted with. Eventually, we will consider these expectations in the context of the practice of neurosciences and the normality regime, under which we understand the set of rules, norms and conventions that transport the idea of a competent actor equipped with certain stereotypical characteristics or abilities becoming the norm from which everyone is excluded who defies it.

\section{Ability Expectations}

"Ability expectation simply signifies that one desires or expects certain abilities" [32]. While those abilities can contain a wide scale and spectrum [33], for the purposes of this study, we confine them to the ones that individuals may have and the ones that are expected from them. These expectations do not necessarily stem from other individuals or collectives. Objects or artefacts can also carry certain ability expectations as they have been designed to do certain things. According to Aristotle, a knife's ergon (usually translated as "function") is to cut well. As such, it presupposes or expects somebody who has the ability to handle the knife. That means that somebody has the skills and knowledge how to use a knife and who has the physical substrate necessary to do so, i.e. to have a hand and an arm (or you can be skilled to handle a knife with your foot or in some other way). A telephone presupposes a voice and the motor function to dial numbers and press buttons. The more technical and complex an artefact, the more abilities it may require as driving a race car requires a higher skill set than driving a regular compact car. At the same time, often the more technology an artefact contains, the more physical activities are being abandoned. An escalator replaces climbing stairs, emails replace handwritten letters which need to be taken to a post box or office, an e-bike does most of the pedalling for you, and so on.

Like every other technology, BCIs are also fraught with two kinds of ability expectations. There are ability expectations of the users and there are ability 
expectations from the user. The former refer to ability expectations regarding what users can or do expect from the technology. For the case of BCIs, these would be the aforementioned aspects such as more independence or communication opportunities. The latter are ability expectations regarding what the technology requires from the user. It asks for what-skills, competences, attitudes, and resources - is expected from the user in order to operate the technology successfully.

These ability expectations from the user are what we want to look at in this study.

\section{Methods and Study Participants}

The data material used stems from a qualitative interview study with persons who have used BCIs for therapeutic reasons [30]. Nine semi-structured interviews were conducted with BCI users who have participated in medical BCI studies with persons with physical impairments. The participants for the study were contacted directly or through BCI researchers or through persons we had interviewed before. Some interviews were held face-to-face, some were conducted via video call, and for some interviews, personal visits and written communication were combined. One interviewee preferred to communicate entirely via email due to severe speech impairments. All interviewees declared informed consent for their participation in the interview study.

Three interviews (Robert, Neil and Nicole) were held in English, while the others were conducted in German. German transcriptions that are displayed in this article as interview citations were translated into English by the authors.

The interviews were transcribed verbatim and analysed following the Grounded Theory coding procedure $[34,35]$. The interviews aimed for experiences, evaluation and self-perceptions of the BCI users.

The participants of the interview study vary in terms of nationality (the sample comprised six participants from Germany, two from the US and one from France), gender, age, diagnosis, BCI applications used and BCI experience (see Table 1). All BCIs that were operated were either active or reactive BCIs. ${ }^{1}$

\footnotetext{
${ }^{1}$ In active BCI settings, users need to perform a mental task, such as imagining moving a body part. The recorded brain signals of motor imagery are translated into a specific BCI output. In reactive BCI settings, users need to direct focused attention to specific stimuli. The $\mathrm{BCI}$ then detects the brain activity that occurs when the stimuli occurs the users are concentrating on.
}

A heterogeneous sample of study participants bears strengths and weaknesses. Given the variety of physical impairments and BCI applications used, one cannot make general statements on either. There is a need for more research on user groups with the same physical impairments and users that work with the same BCI model. At the same time, the heterogeneity of the sample allows for a rich overview on various BCI-related aspects. Focussing on ability expectations that users experienced, we shall see that similar experiences can be identified among the participant group.

\section{Brain-Computer Interfaces and Expected Abilities}

Addressing the perspective of users that have operated or have been operating a $\mathrm{BCI}$ in clinical experimental studies, we wanted to find out what abilities are expected by a BCI or, to be precise, which expectations are implicated in its use. Some of them - as we will showare explicit and some are implicit expectations (see Fig. 1). Some expectations stem from the organizational setup of the BCI studies and are due to the BCI model that is supposed to be tested and the research interests of the BCI researchers. Some expectations depend on the technology and the respective tasks and the programmes and devices on which these are performed. Some are directed towards the users' overall attitude and personal characteristics.

\section{Explicit Ability Expectations}

For experimental studies that are set out to test some medical technology such as brain-computer interfaces (or to be precise: technologies that are also used for medical applications), study participants are sought according to various qualifications. First of all, participants are selected according to certain formal criteria. They are supposed to have particular motor functions and dysfunctions. The researchers look, for instance, for persons that suffered an apoplectic stroke or are paraplegic while at the same time should not display any cognitive infringements or restrictions, should not have spasms or epilepsy, should not have a cardiac pacemaker or other implanted devices, etc. In addition, there is often an age limitation which excludes potential participants which exceeded the postulated age limit. Usually, the study participants should also be able to give their informed consent to their participation in the respective study. 
Table 1 Participants (names pseudonymized) of the interview study (source: Kögel et al. [30])

\begin{tabular}{|c|c|c|c|c|}
\hline $\begin{array}{l}\text { Participants } \\
\text { (name, age) }\end{array}$ & Diagnosis & Technologies used & BCI technology (applications) & $\begin{array}{l}\text { Number of BCI } \\
\text { (training) sessions }\end{array}$ \\
\hline Stefan, 24 & $\begin{array}{l}\text { Generalized } \\
\text { dystonia }\end{array}$ & Wheelchair, eye tracker, computer & $\begin{array}{l}\text { NIRS-BCI (near-infrared } \\
\text { spectroscopy), non-invasive }\end{array}$ & 1 \\
\hline Walter, 32 & Muscle atrophy & $\begin{array}{l}\text { Wheelchair, email/typing and voice recognition } \\
\text { software, computer, respiration apparatus }\end{array}$ & $\begin{array}{l}\text { P300-BCI (email-Software, } \\
\text { Brain Painting), } \\
\text { non-invasive }\end{array}$ & 3 \\
\hline $\begin{array}{l}\text { Wolfgang, } \\
\quad 31\end{array}$ & Muscle atrophy & $\begin{array}{l}\text { Wheelchair, email/typing and voice recognition } \\
\text { software, computer, respiration apparatus }\end{array}$ & $\begin{array}{l}\text { P300-BCI (email-Software, } \\
\text { Brain Painting), } \\
\text { non-invasive }\end{array}$ & 3 \\
\hline Karl, 46 & $\begin{array}{l}\text { Duchenne } \\
\text { muscle } \\
\text { dystrophy }\end{array}$ & $\begin{array}{l}\text { Wheelchair, email/typing software, computer, } \\
\text { respiration apparatus }\end{array}$ & $\begin{array}{l}\text { P300-BCI (email-Software, } \\
\text { Brain Painting), } \\
\text { non-invasive }\end{array}$ & Ca. 20 \\
\hline $\begin{array}{l}\text { Mrs. } \\
\text { Edlinger, } \\
77\end{array}$ & $\begin{array}{l}\text { Amyotrophic } \\
\text { lateral } \\
\text { sclerosis }\end{array}$ & $\begin{array}{l}\text { Wheelchair, email/typing software, computer, } \\
\text { BCI }\end{array}$ & $\begin{array}{l}\text { P300-BCI (Brain Painting), } \\
\text { non-invasive }\end{array}$ & $>100$ (ongoing) \\
\hline Rudi, 27 & Tetraplegia & Wheelchair, computer & $\begin{array}{l}\text { MI-BCI (motor imagery) } \\
\text { (BrainRunners), } \\
\text { non-invasive }\end{array}$ & $>50$ \\
\hline Robert, 51 & Paraplegia & Wheelchair, computer & $\begin{array}{l}\text { MI-BCI (+exoskeleton } \\
\text { training), non-invasive }\end{array}$ & $>50$ (ongoing) \\
\hline Neil, 30 & Tetraplegia & $\begin{array}{l}\text { Wheelchair, email/typing and voice recognition } \\
\text { software, computer }\end{array}$ & $\begin{array}{l}\text { MI-BCI (+ robotic arm), } \\
\text { invasive (implanted } \\
\text { electrodes) }\end{array}$ & $>50$ (ongoing) \\
\hline Nicole, 58 & $\begin{array}{l}\text { Spinocerebellar } \\
\quad \text { ataxia }\end{array}$ & $\begin{array}{l}\text { Wheelchair, email/typing and voice recognition } \\
\text { software, computer, respiration apparatus }\end{array}$ & $\begin{array}{l}\text { MI-BCI (+ robotic arm), } \\
\text { invasive (implanted } \\
\text { electrodes) }\end{array}$ & $>100$ \\
\hline
\end{tabular}

If the candidates managed to meet the qualifications needed for the study according to the formal criteria, they need to go through a test run to determine whether they are able to steer the BCI. As the BCI is not a "one size fits all" application, it works better among some individuals and worse among others. Some persons that are not able to operate a BCI at all are sometimes called "BCI illiterate". ${ }^{2}$ It may be due to the fact that they are not able to concentrate, imagine or think in ways that are required of them or it is simply due to the physical setup. Every brain is wired differently and therefore an EEG-cap using electrodes to match a particular positional matrix can detect brain signals of some persons better than of others. Also, the thickness or thinness of one's scalp and its level of sensitivity can play a role. It has also been shown that being "BCI illiterate" for one particular $\mathrm{BCI}$ device does not mean that you are unable to operate a BCI in general. Some individuals that could not manage a particular BCI were in fact able to work with another one [36, 37].

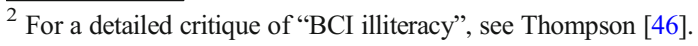

In addition, users are not supposed to display any involuntary body movements such as the aforementioned spasms or epilepsy, as it can distort the brain signals and can affect the physical set-up. In this case, it may not be BCI "illiteracy", but it practically leads to not useable results. In some cases, residual competencies in body movements can be detrimental for BCI use as it becomes difficult to prove that BCI output is generated by your imagination or your thoughts only and not from some residual nerval activity in your body parts.

If someone does not match these requirements, there will be no BCI study participation for that particular person. When you meet these requirements and move on to become a study participant in BCI testing, there will be implicit expectations that apply.

\section{Implicit Ability Expectations}

There are various expectations that are implicit to successful BCI use, may it be due to unspoken expectations of the BCI researchers, the time, money and mobility that are needed for participating in the BCI training or 


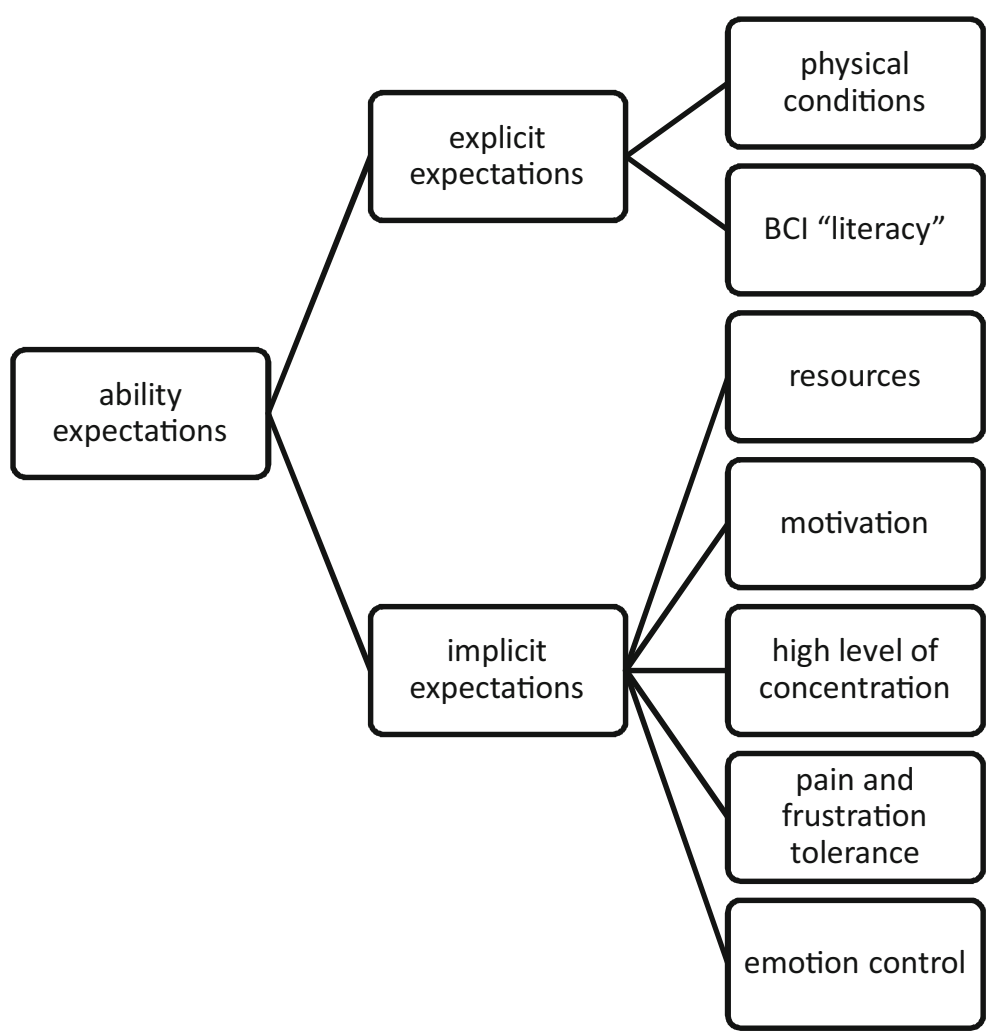

Fig. 1 Overview on explicit and implicit ability expectations

mechanisms and functions that are inherent to the $\mathrm{BCI}$ technology.

First of all, participation in an experimental BCI study requires resources. While being present at the training sessions is kind of an explicit requirement, it presupposes having a lot of free time at your disposal. One user is regularly driving more than an hour to the $\mathrm{BCI}$ trainings. In addition to the four hours of $\mathrm{BCI}$ training, you spend almost seven hours a day on the training. That requires an additional time disposal as well as mobility. You need to organize transportation and in case you cannot drive yourself, a driver as well. In case you do not have a car, you need to organize somebody who has a car or can organize public transportation. Many users then are also dependent on being accompanied by a care-giver. Being in need of a professional care-giver results in additional financial and personal (staff) resources. Therefore, resources such as time, costs and transportation play their part in $\mathrm{BCI}$ usage. In addition, while having a $\mathrm{BCI}$ at home may theoretically be an alternative,

"the other main con I did think of is just the sheer price, right, this isn't, it's not ready for, you know, home consumers. You know, there's probably $\$ 1$ million worth of equipment in the room I go into for testing" (Neil).

In case you want to use a BCI privately at home in addition to or after the BCI study is finished, you would need to be able to pay an exceedingly large amount of money. This is not a precondition to get enrolled into BCI studies and hence not an implicit expectation. Nevertheless, it is something users are concerned with as they know they will not be able to use a BCI beyond the end of the study, given that BCIs are still experimental devices that are not available on the mainstream market yet.

Another aspect that is certainly presupposed is motivation of the participants. This however may be simply assured through the formal application process, which probably implies the participants' motivation in completing the application. All of the BCI study participants interviewed reported of being motivated to do the BCI testing. Some were just curious, some felt like contributing to technological progress as an important endeavour, and some expected the BCI training to improve their physical health. Many users realized quickly that the BCI would not benefit them at the current stage. As 
long as they have voluntary control over body movements, any programme steered via key, joystick control or eye tracker still proves to be superior to BCIs in terms of speed and efficiency. The challenge is then to stay motivated nevertheless. Users stressed that even though recognizing that $\mathrm{BCIs}$ cannot make any contribution to their health or well-being at the moment, they found it important to play their part in medical progress, hoping that future generations with similar physical conditions will have a technology at hand they can benefit from.

$\mathrm{BCI}$ testing means training sessions of several hours a day, sometimes a few days a week. All the BCI users of the interview study were very motivated to complete the BCI training and partly reported of high levels of joy and satisfaction they gained from using a BCI. At the same time, they experienced the training with the $\mathrm{BCI}$ as a very exhausting task. This is mainly due to the high level of concentration that is being required of them.

Particularly the mental strategy of selective attention that is peculiar to reactive BCIs demands a high level of focused performance. This setting always requires the same amount of attention. Therefore, a routinization of the task does not take place. "It's always very exhausting" (Mrs. Edlinger), stresses one user regarding BCI usage. In theory the task at hand is rather simple:

"It's not very difficult as such. To get the idea of it, to comprehend its principle, is not difficult. But it is hard to execute without any mistakes-that it always recognizes what you want it to do. But as such it's not difficult to comprehend"' (Wolfgang).

In practice, the task proves to be quite challenging, however:

"I had to concentrate on what to choose. That requires - that wasn't easy. You really need to focus. You mustn't get distracted somehow" (Wolfgang).

This view is shared by the users operating a reactive BCI:

"The so-called P300 wave of your brain realizes when you reached the necessary level. Only then the positive result is flashing up. Consequently, it's no piece of cake" (Mrs. Edlinger).

While the principle of the selective attention model is pretty easy, performing this exercise over long periods of time (up to $45 \mathrm{~min}$ ) can become a tedious and exhausting task:

"Well, for each and every letter you have to fight actually" (Wolfgang).

According to these accounts, BCI training is described as hard work where each command needs to be "fought for". But also sensomotoric BCIs, i.e. BCIs working with motor imagery, are experienced as exhausting.

"It's intense. After training I always feel like I'm knocked out. You could chuck me in the dustbin. There is not much I still can do" (Rudi).

There are tasks that are perceived as more challenging and exhausting than others.

"Training was once a week [...] then twice a week and at the end [...] we met three times a week, which was super exhausting. [...] Training was super exhausting because you had to think the whole time-that is, you may think and you may not think or to think of particular things and not to think. These were about the commands which I had for the competition. Especially NOT to think is ULTRA difficult and also as good as not possible, because every human is thinking somewhat all the time" (Rudi).

Trying to think of nothing has been perceived as particularly difficult. For this exercise, you are supposed to be as relaxed as possible as the kind of brain signals that are required for the task are associated with a state of relaxation. At the same time, you are supposed to perform a task which is perceived as difficult. This leads to quite a challenging task when you need to bring these opposing targets into balance.

Robert reports of another challenge he was facing during $\mathrm{BCI}$ training:

"After a while, coming regularly twice a week and after a while once a week, it was useful also to try to figure out my body. It's something that I never did before and it was quite difficult. It seems easy but it was quite difficult" (Robert).

Paying attention to your own body and its bodily sensations can be an unfamiliar task and something 
which is not achieved easily when you are not used to these things. Rudi also indicated that BCI training was not only physically but also mentally tiring.

"When you have to concentrate the whole time and to concentrate profoundly -I had to concentrate SO hard, as I have never done in my life before. And I needed to be in control of myself. [...] When you just think of your right hand and when you look at my right hand now, then there are muscles twitching. In my tendons there is some minimal movement and I had to control this somehow. That is-I did get to know my body in a new way. The one command, for example, was to step on the brakes. My legs were so heavy and did hurt so badly. [...] Or my arms were cramping because I was drawing eights with my right hand, the infinity symbol. Mentally, that's just about the limit! I completely underestimated that in the beginning because I hadn't thought that it will be that intense and it wears you out in such a way" (Rudi).

However, in sensomotoric BCI training, routinization is possible and the initial feeling ("quite strange at the beginning") may be replaced by routine and ease of use.

"I should say, a little bit exhausted at the beginning when I was doing on my wheelchair. I was more exhausted at the beginning, when I was in the exosquelette [sic]. [...]but after a while I get used to and it was better, better and better, I should say" (Robert).

So far, we have seen that BCI training requires a level of concentration which is out of the ordinary and therefore is experienced as tiring and exhausting. Furthermore, $\mathrm{BCI}$ training can be very challenging on the body and can cause bodily pain. Also, being in the same position as well as wearing the EEG cap for a long time has been described as uncomfortable. One user volunteered for using metallic syringes instead of the plastic ones to apply the gel on the scalp to fix the electrodes as the plastic ones did not seem to work.

"Then I said 'Well, the metallic syringes then!' They hurt and I tended to bleed a little on my head, but I didn't care. Most importantly we got the perfect results" (Rudi).
Hence, having a high level of pain tolerance is of advantage in at least some BCI training. As not all $\mathrm{BCI}$ activities are successful, especially in the beginning of the training, patience and being able to cope with frustration is a necessary ability.

"Everything needs to be set up perfectly and the electrodes need to be applied correctly. Otherwise the success rate is low or it doesn't work at all and you get frustrated" (Mrs. Edlinger).

Another cause of frustration can be boredom, as not all exercises are experienced as exciting or challenging.

"I pick whatever numbers there are, and the rules are, if it feels double what the last was, say a number that's double, it feels half, I say half. And it's really boring and sometimes I just feel weird because I feel like I'm just making numbers up but then they keep telling me, like, when they actually analyse the data, like, you know, they go 'Oh you're really good at it, like, you know, you're telling us 16, you know, it makes a nice straight line on the path', but it's really boring. Well, science can't all be super fun, so I get a lot of it' (Neil).

Robert who started training with a BCI that was connected to an exoskeleton reports of his state of mind when finding himself in an upright position after having got used to sitting in a wheelchair.

"At the beginning, since I haven't been standing for years or ages, I was frightened [...] I was stressed, really stressed, scared and they were really there to help me, to say, secure the-they attach things in the exosquelette [sic] in case I was rolling or whatever. Everything was in a perfect thing, but it was me to be stressful. But after some weeks, it was fine" (Robert).

As exciting as BCI training may be for its users, it does not come without moments of stress and anxiety.

Coming back to the concentration that is expected from BCI users, the challenge is not only about paying attention over long periods of time, but also not to get distracted. The success of BCI actions is dependent on concentration. 
"It depends on how concentrated you are. The more you are concentrated and the less distraction there is, the better it works" (Karl).

One user reports of a day when the success rate of the $\mathrm{BCI}$ training was quite low:

"You mustn't get distracted in any way. I can remember one time there was a construction site outside. The room had a window and underneath that window was a construction site with construction vehicles and they made a noise and on this day my measurements didn't work very well. [...] It may be that this was due to the noise of the construction site that distracted me" (Wolfgang).

Besides external sources for distraction, they can also have an internal cause.

"I always say brains are dumb but really it's sometimes, computers are dumb at figuring out what your brains are thinking, so some days it's, especially if I haven't slept well the night before and I'm already tired, sometimes the stuff just doesn't work super good. [...] Sometimes the, the programming isn't that great. But yes, and then sometimes robots are super durable, sometimes they just wear down or overheat and so there are still many points of failure that are possible in these systems" (Neil).

Being tired can be an issue during BCI training, and affective factors can contribute to poor BCI outcomes.

\begin{abstract}
"I still remember my first training. I started to get to know somebody and then she said before the training 'It's not working out with the two of us.' Well, then my thoughts were completely somewhere else and then trying to calm down-hence, logically that training session was shit. You have these influences. Or when my pet died-you naturally have these influences, every human. That's the thing with not thinking. You automatically have something your mind wanders to. That's how it is" (Rudi).
\end{abstract}

Getting emotional or being preoccupied with different thoughts can have a negative impact on the BCI training. The BCI training can easily lead to a vicious circle of frustration and unsuccessful BCI output because unsuccessful commands can lead to further frustration.

"I was NOT allowed to get upset in that moment because that would have been a wrong signal and would have distorted the training and the competition. You really must NOT have emotions, none whatsoever-completely, you had to be completely dead inside, in that sense" (Rudi).

This imperative of no emotions has also been reported by other users. Robert, for example, reports of this issue in particular in case of wrong commands that came as a surprise:

"That's quite difficult for me, because sometimes I thought I could really focus and concentrate and it was quite a surprise. For instance, you don't answer properly. That means, [I] was thinking on the right and it was the left and when it was like that I shouldn't have-I should really not care about because if I care it's even worse. That means that the next round, it goes wrong also. Next try sorry, it goes wrong because I have too much focus on why, why, why so I try to say 'Okay, I don't know' [...] so I try not to figure out why because I don't-frankly I don't understand. If I try to really focus too much, this has an impact on the second try or the third try" (Robert).

Distractions, such as emotional baggage you are carrying as well as feeling surprise in situations where you are confronted with an unexpected outcome and start to doubt yourself as a consequence, are very common and very human processes. To suppress these emotional factors in order to focus on cognitive exercises appears to be a very challenging task.

To simply bring your cognitive abilities to BCI training and to cut off your affective side certainly must seem impossible. Emotion control therefore turns into quite a challenging ability expectation. The feeling that you need to abandon your emotions when coming to the training may also be a factor that permits completely embracing the technology and a total routinization of $\mathrm{BCI}$ activities.

That is not to say that it cannot be achieved at all. One user who has implanted electrodes achieves this level of $\mathrm{BCI}$ control quite regularly: 
"I always say it was really cool at first and now it's just second nature. Like, it's just, it's a thing I can do at this point. I mean, it's still really cool, but it's just a thing I can do and it's pretty easy to do. It's just almost like I could always have done it before" (Neil).

This may be due to the fact that he has implanted electrodes or maybe he knows how to control his emotions better or a mix of both. Nevertheless, keeping your emotional side out of BCI training is a challenge for many users and must seem like a super-human endeavour. The super-human here refers to an individual that is capable of retaining control of oneself in terms of calling up one's cognitive abilities (first of all concentration) while at the same time suppressing any potential causes of distraction (noise, fatigue, boredom, emotions, and affective reactions).

It should not be forgotten that BCIs are devices that are meant to be for humans and are supposed to increase the quality of life for their users. It therefore should be taken into account that BCI users have emotions and in the best case can be included somehow in the technology's make-up.

Towards a "Disembodied Mind"?

Taking the example of brain-computer interfaces, Melike Şahinol [38] examines the practice of neuroscience in which she finds a Cartesian worldview being at work, a "Cerebro-Centrism" that is inherent in neuroscience. While Vidal and Ortega [39] recognize the tendency within - but not restricted to - the neurosciences of having established the notion of a "cerebral subject" accompanied by the "creed" of understanding ourselves as our brains in the first place, Şahinol identifies a "techno-cerebral subject" where the cerebral subject is produced and maintained by means of technology.

Reducing the BCI study participants to their cerebral functions by detaching brain processes from the users' bodily experiences may also have an effect on the users' self-perception in objectifying one's body. The feeling of some users that they need to pitch for BCI training with their cognitive abilities on board while being expected to leave their affective aside at the front door, certainly can be read as pointing into that direction.
Asked if the BCI training changed her self-image, one user responded:

"Oh, God, it really changed my self-image. It changed, as I said, the empowerment, the feeling, 'I did this, look what I can do.' It helped me realize that-I have a saying up on my wall, 'You are more than the body you live in.' I just realized the truth of that statement, that my brain was the most important part of me, and that working meant I could do a lot" (Nicole).

BCI training gave Nicole a feeling of empowerment and had a positive impact on her self-esteem. At the same time, the BCI training gave rise to some "brainification" process. Nicole adjusts her self-image and body-image in a way that prioritizes her brain. It may be telling that she does not refer to her mind or her power of thought, but her brain. During BCI training she made the experience that "my brain had not forgotten" (Nicole). In virtue of her brain, which is still as functional as before, she becomes empowered over her body. As we do not have introspection of our brain, but just of our mind, it can be argued that Nicole actually refers to her mind when making these statements, and because the brain is broadly regarded - according to a dualistic or "Cartesian world view" - as the carrier or physical substrate for the mind, she speaks of the brain instead. Within the research situation and the BCI set-up, this is logical, as what is measured is brain activity and not her thoughts or mental processes.

The consequence is a view of a passive body which is controlled by means of a working mind/brain complex that depicts the centre of a seemingly bodiless or disembodied subject or individual. We do not intend to evaluate any normativity in this view, in particular as we have seen, that a reductionist and body objectifying view on humans also can transport or at least can be accompanied by experiences of empowerment. To put this into perspective, we would rather have a look at the context of two other theorizations of disembodiment, namely the theory of "the two bodies" of Mary Douglas [40], in particular the "purity rule", and the notion of the "disembodied mind" within an order of normalization according to Ingunn Moser [41].

In her renowned discussion of "the two bodies", Mary Douglas proposes the so-called "purity rule", according to which the stronger the pressure of a social system, the more it seeks to disembody forms of 
expression. The degree of disembodiment reflects social hierarchy. The more subtle, refined and controlled the behaviour someone displays, the higher someone is ranked in terms of social standing and degree of civilization. Given that BCI actions, due to bypassing the peripheral nervous systems, are examples par excellence for disembodied actions, what does that mean according to the purity rule? Does it turn BCI users into the most noble of humankind? This seems very unlikely. It seems more likely that the gulf between disabled and non-disabled users will be perpetuated if not even furthered. The latter may be seen as the ones that are enhancing themselves by means of BCI use, while the former may depend on it for assistance. Non-disabled users perform better with some BCI applications than disabled users, while the underlying causes are still contested $[42,43]$. The grade of (residual) body movement and motor control also impacts the match of respective BCI models $[44,45]$. Also the medication, may it be muscle relaxants or other substances, can have an effect on BCI performance and often is an exclusion criterion for BCI studies. Eventually, new lines of demarcation or discrimination may become manifest, for example along the criterion of BCI "literacy" [46].

Persons with disabilities see themselves confronted with a high level of social control and under a "mode of ordering geared towards normalization" [41]. Under such a normality regime "the normal competent actor is discontinuous, bounded and detached" [41]. That means that an individual has a natural, bounded body, that is not attached to anything such as technologies or devices, and has the disposition to act whenever it feels like it (therefore discontinuous). Individuals with disabilities may have the same agency; it just may be more distributed, encompassing people and technologies. Agency in general, argues Moser, is always mediated and distributed. The difference lies in the attribution of agency. Individuals that meet the standard model of the "normal competent actor" are solely credited with agency while everything else, all enabling practices and relations, even their bodies, are made invisible. These individuals are regarded and treated like "disembodied minds". The opposite holds true for people with disabilities. Here, "the heterogeneous materiality and embodiment is much more present and visible" [41]. This means, we cannot see the BCI output as disembodied actions; we always turn attention to the technological devices, the computer, the screens, the cables, the EEG cap one is wearing or whatever electrodes someone is attached to, perhaps also prostheses or robotic devices, probably also the environment of the laboratory, and the scientists and research staff present. The reason for that is: "It does not fit with the standardized environments that allow agency to flow without constant interruption" [41]. As a consequence, people with disabilities are also disabled in regard to being neglected the possibility of performing a "disembodied mind".

The consequence then is that due to this normality regime $\mathrm{BCI}$ users are expected to operate the BCI technology and perform actions with it while at the same time the attribution of agency is being denied. This can be read as further ability expectation imposed upon BCI users: being able to perform BCI actions, knowing that the credit (or agency) will not be attributed to you alone. As has been shown, BCI users get credit for their achievements of BCI training and also are able to take advantage of that even after the BCI research studies had been concluded [30]. However, the credit is not the user's only, but also goes to the engineer(s) who developed the technology. For comparison reasons we may ask: What credit goes to the car (and its production company) of a motor race winner? What credit goes to the shoes (and its manufacturer) of a star sprinter?

Coming back to the purity rule, it will be a matter of the future to see what standing it will have as a disembodied way of acting, in particular in contrast to $\mathrm{BCI}$ applications developed for non-disabled users. The issue of disembodied BCI actions may yet be telling when taking into account another aspect of Douglas' theory, namely the hypothesis of the "concordance between social and bodily expressions of control" [40]. According to Douglas, we aim "to achieve consonance in all levels of experience" [40], i.e. the levels of the social and the physical (and she also adds the emotional at a later stage). As the social level appears to be the constraining part in this equation, we may have to look at the social dimension of $\mathrm{BCI}$ use.

Accordingly, the ability expectations from BCI users outlined previously can be explained by analogy: here, it is between a socially transported ideal concept of the human (the social level of control) — one could say, the aforementioned "normal competent actor"- and the requirements of the user (the bodily level of control). The perfect BCI user then, according to the identified ability expectations, i.e. a cognitively sharp individual, exerting a high degree of emotional control, being motivated and having a minimum of resources at its disposal, probably is not far from what may be regarded as a stereotype of 
the human ideal according to Western civilization (as a human, agent, subject, citizen, consumer, or worker). As a consequence, the integration of emotion detection in BCIs may be deemed to be of less importance. Nevertheless, the research on affective BCIs has seen rapid development [47, 48].

Douglas wrote in an earlier publication: "Any culture is a series of related structures which comprise social forms, values, cosmology, the whole of knowledge and through which all experience is mediated. Certain cultural themes are expressed by rites of bodily manipulation" [49].

Applied to today's Western society, neuroscience and BCI use, it could be stated:

The societal portrayal of the human as mind-body complex with its focus on the importance of the brain, finding its resonance and cause or consequence in neuroscience, trickles down to the ability expectations towards technology users and their respective self-image/ body-image.

\section{Conclusion}

Shifting the focus from what BCIs can bring to the user to what the user must bring to BCI training rendered various requirements that we classified as ability expectations. As we have seen, training requires quite a tremendous mix of various skills and resources on the side of the users. First of all, a particular physical condition is required showing particular motor impairments while at the same time being in control of one's cognitive abilities and to be BCI "literate". Being able to stay focused on the tasks at hand for long periods of time while staying motivated and in control over one's affections and emotions displays a particularly challenge. BCI training requires sustaining circumstances we are not used to in everyday life. In addition, patience and tolerance towards pain and discomfort as well as being able to deal with frustration are preconditions for a successful BCI turnout. All in all, BCI use requires a package of various skills and competencies, bound together with will power and discipline which may appear as a job description seeking for participants with almost superhuman powers. At least it should suffice to illustrate the impressive work and enormous performance achieved by BCI users. As BCI technicians are about to design devices in a more user-friendly way, we are likely to see $\mathrm{BCIs}$ in the future that will work with less or lower ability expectations, which users will be confronted with. However, we have seen that the ability expectations that have been identified do not come out of nothing, but rather have a social grounding. Hence, we cannot be too certain about these improvements, as technological development is not independent from the portrayal and conceptualisation of "the human" in neuroscience in particular and society in general.

Availability of Data and Material The data sets generated and analysed during the current study are not publicly available, because a significant proportion of them identify people and organizations. Anonymous subsets are available from the corresponding author on reasonable request.

Funding Open Access funding enabled and organized by Projekt DEAL. The interview citations stem from an interview study that has been funded by a grant from the German Federal Ministry of Education and Research (01GP1622A) within the ERA-NET Neuron programme. The funders were not involved in data collection or analysis or writing of this article.

\section{Compliance With Ethical Standards}

Ethics Approval and Consent to Participate The study has been approved by the Ethics Committee of the Medical Faculty of the LMU Munich (Ethikkommission bei der Medizinischen Fakultät der Ludwig-Maximilians-Universität München) (Number: 575-16). Written informed consent was obtained from the participants for publication of their cases and any accompanying tables. A copy of the written consent is available for review by the Editor of this journal.

Consent for Publication Participants declared informed consent for using data assessed in publications.

Competing Interests The authors declare that there is no conflict of interest.

Open Access This article is licensed under a Creative Commons Attribution 4.0 International License, which permits use, sharing, adaptation, distribution and reproduction in any medium or format, as long as you give appropriate credit to the original author(s) and the source, provide a link to the Creative Commons licence, and indicate if changes were made. The images or other third party material in this article are included in the article's Creative Commons licence, unless indicated otherwise in a credit line to the material. If material is not included in the article's Creative Commons licence and your intended use is not permitted by statutory regulation or exceeds the permitted use, you will need to obtain permission directly from the copyright holder. To view a copy of this licence, visit http://creativecommons.org/licenses/by/4.0/. 


\section{References}

1. Wolpaw JR, Wolpaw EW (2012) Brain-computer interfaces: principles and practice. Oxford University Press, Oxford

2. Bouton CE, Shaikhouni A, Annetta NV, Bockbrader MA, Friedenberg DA, Nielson DM, Sharma G, Sederberg PB, Glenn BC, Mysiw WJ (2016) Restoring cortical control of functional movement in a human with quadriplegia. Nature 533(7602):247-250

3. Graimann B, Allison B, Pfurtscheller G (2009) Braincomputer interfaces: a gentle introduction. In: Graimann B, Pfurtscheller G, Allison B (eds) Brain-computer interfaces. Springer, Berlin, pp 1-27

4. Mak JN, Wolpaw JR (2009) Clinical applications of braincomputer interfaces: current state and future prospects. IEEE Rev Biomed Eng 2:187-199. https://doi.org/10.1109 /rbme.2009.2035356

5. Marchetti M, Priftis K (2015) Brain-computer interfaces in amyotrophic lateral sclerosis: a metanalysis. Clin Neurophysiol 126(6):1255-1263. https://doi.org/10.1016/j. clinph.2014.09.017

6. Wolpaw JR, Birbaumer N, McFarland DJ, Pfurtscheller G, Vaughan TM (2002) Brain-computer interfaces for communication and control. Clin Neurophysiol 113(6):767-791

7. Daly JJ, Wolpaw JR (2008) Brain-computer interfaces in neurological rehabilitation. The Lancet Neurology 7(11): 1032-1043

8. Chaudhary U, Birbaumer N, Ramos-Murguialday A (2016) Brain-computer interfaces for communication and rehabilitation. Nat Rev Neurol 12(9):513-525. https://doi. org/10.1038/nrneurol.2016.113

9. Maksimenko VA, van Heukelum S, Makarov VV, Kelderhuis J, Lüttjohann A, Koronovskii AA, Hramov AE, van Luijtelaar G (2017) Absence seizure control by a brain computer interface. Sci Rep 7:2487

10. McFarland DJ, Daly J, Boulay C, Parvaz MA (2017) Therapeutic applications of BCI technologies. BrainComputer Interfaces 4(1-2):37-52

11. Zafar MB, Shah KA, Malik HA Prospects of sustainable ADHD treatment through brain-computer interface systems. In: Innovations in Electrical Engineering and Computational Technologies (ICIEECT), 2017 International Conference on, 2017. IEEE, pp 1-6

12. Glannon W (2014) Neuromodulation, agency and autonomy. Brain Topogr 27(1):46-54. https://doi.org/10.1007 /s10548-012-0269-3

13. Friedrich O, Racine E, Steinert S, Pömsl J, Jox RJ (2018) An analysis of the impact of brain-computer interfaces on autonomy. Neuroethics. https://doi.org/10.1007/s12152-0189364-9

14. Kleih SC, Kübler A (2014) Psychological perspectives: quality of life and motivation. In: Grübler G, Hildt E (eds) Brain-computer-interfaces in their ethical, social and cultural contexts. Springer, Dordrecht, pp 77-84

15. Holz E (2015) Systematic evaluation of non-invasive braincomputer interfaces as assistive devices for persons with severe motor impairment based on a user-centred approach - in controlled settings and independent use. Universität Würzburg, Würzburg
16. Holz EM, Botrel L, Kaufmann T, Kübler A (2015) Longterm independent brain-computer interface home use improves quality of life of a patient in the locked-in state: a case study. Arch Phys Med Rehabil 96(3 Suppl):S16-S26. https://doi.org/10.1016/j.apmr.2014.03.035

17. Holz EM, Botrel L, Kübler A (2015) Independent home use of brain painting improves quality of life of two artists in the locked-in state diagnosed with amyotrophic lateral sclerosis. Brain-Computer Interfaces 2(2-3):117-134

18. Nijboer F, Birbaumer N, Kübler A (2010) The influence of psychological state and motivation on brain-computer interface performance in patients with amyotrophic lateral sclerosis - a longitudinal study. Front Neurosci 4:55. https://doi.org/10.3389/fnins.2010.00055

19. Holz EM, Höhne J, Staiger-Salzer P, Tangermann M, Kübler A (2013) Brain-computer interface controlled gaming: evaluation of usability by severely motor restricted endusers. Artif Intell Med 59(2):111-120. https://doi. org/10.1016/j.artmed.2013.08.001

20. Cincotti F, Mattia D, Aloise F, Bufalari S, Schalk G, Oriolo G, Cherubini A, Marciani MG, Babiloni F (2008) Noninvasive brain-computer interface system: towards its application as assistive technology. Brain Res Bull 75(6):796803. https://doi.org/10.1016/j.brainresbull.2008.01.007

21. Zickler C, Halder S, Kleih SC, Herbert C, Kübler A (2013) Brain painting: usability testing according to the usercentered design in end users with severe motor paralysis. Artif Intell Med 59(2):99-110

22. Pedrocchi A, Ferrante S, Ambrosini E, Gandolla M, Casellato C, Schauer T, Klauer C, Pascual J, Vidaurre C, Gfohler M, Reichenfelser W, Karner J, Micera S, Crema A, Molteni F, Rossini M, Palumbo G, Guanziroli E, Jedlitschka A, Hack M, Bulgheroni M, d'Amico E, Schenk P, Zwicker S, Duschau-Wicke A, Miseikis J, Graber L, Ferrigno G (2013) MUNDUS project: MUltimodal neuroprosthesis for daily upper limb support. Journal of Neuroengineering and Rehabilitation 10:66. https://doi.org/10.1186/1743-000310-66

23. Schicktanz S, Amelung T, Rieger JW (2015) Qualitative assessment of patients' attitudes and expectations toward BCIs and implications for future technology development. Front Syst Neurosci 9:64. https://doi.org/10.3389 /fnsys.2015.00064

24. Zickler C, Di Donna V, Kaiser V, Al-Khodairy A, Kleih S, Kübler A, Malavasi M, Mattia D, Mongardi S, Neuper C, Rohm M, Rupp R, Staiger-Salzer P, Hoogerwerf E-J (2009) BCI applications for people with disabilities: defining user needs and user requirements. Paper presented at the 10th European Conference for the Advancement of Assistive Technology.

25. Blabe CH, Gilja V, Chestek CA, Shenoy KV, Anderson KD, Henderson JM (2015) Assessment of brain-machine interfaces from the perspective of people with paralysis. J Neural Eng 12(4):043002. https://doi.org/10.1088/1741-2560/12 /4/043002

26. Kageyama Y, Hirata M, Yanagisawa T, Shimokawa T, Sawada J, Morris S, Mizushima N, Kishima H, Sakura O, Yoshimine T (2014) Severely affected ALS patients have broad and high expectations for brain-machine interfaces. Amyotrophic Lateral Sclerosis \& Frontotemporal 
Degeneration 15(7-8):513-519. https://doi.org/10.3109 /21678421.2014.951943

27. Blankertz B, Tangermann M, Vidaurre C, Fazli S, Sannelli C, Haufe S, Maeder C, Ramsey L, Sturm I, Curio G, Müller K-R (2010) The Berlin brain-computer interface: nonmedical uses of BCI technology. Front Neurosci 4. https://doi.org/10.3389/fnins.2010.00198

28. Van Erp JBF, Lotte F, Tangermann M (2012) Braincomputer interfaces: beyond medical applications. Computer-IEEE Computer Society 45(4):26-34. https://doi.org/10.1109/mc.2012.107

29. Kögel J, Schmid JR, Jox RJ, Friedrich O (2019) Using braincomputer interfaces: a scoping review of studies employing social research methods. BMC Medical Ethics 20(1):18. https://doi.org/10.1186/s12910-019-0354-1

30. Kögel J, Jox RJ, Friedrich O (2020) What is it like to use a BCI? - insights from an interview study with braincomputer interface users. BMC Medical Ethics 21(2). https://doi.org/10.1186/s12910-019-0442-2

31. Wolbring G, Diep L (2016) Cognitive/neuroenhancement through an ability studies lens. In: Jotterand F, Dubljevic V (eds) Cognitive enhancement. Oxford University Pres, Oxford, pp 57-75

32. Wolbring G (2012) Citizenship education through an ability expectation and "Ableism" lens: the challenge of science and technology and disabled people. Educ Sci 2:150-164. https://doi.org/10.3390/educsci2030150

33. Wolbring G, Yumakulov S (2015) Education through an ability studies lens. Zeitschrift für Inklusion 10 (2)

34. Strauss A, Corbin J (1990) Basics of qualitative research: grounded theory procedures and techniques. Sage, Newbury Park

35. Charmaz K (2006) Constructing grounded theory. Sage, London

36. Allison BZ, Neuper C (2010) Could anyone use a BCI? Chapter from book. In: Tan DS, Nijholt A (eds) Braincomputer interfaces: applying our minds to humancomputer interaction. Springer, London, pp 35-54

37. Allison BZ, Brunner C, Kaiser V, Müller-Putz G, Neuper C, Pfurtscheller G (2010) Toward a hybrid brain-computer interface based on imagined movement and visual attention. J Neural Eng 7(2). https://doi.org/10.1088/1741-2560/7/2 $/ 026007$
38. Şahinol M (2016) Das techno-zerebrale Subjekt: Zur Symbiose von Mensch und Maschine in den Neurowissenschaften. Transcript, Bielefeld

39. Vidal F, Ortega F (2017) Being brains. In: Making the cerebral subject. Fordham University Press, New York

40. Douglas M (2003) Natural symbols. Routledge, Abingdon, Oxon

41. Moser I (2006) Disability and the promises of technology: technology, subjectivity and embodiment within an order of the normal. Inf Commun Soc 9(3):373-395

42. Friedrich EVC, Scherer R, Neuper C (2013) Userappropriate and robust control strategies to enhance braincomputer interface performance and usability. In: Guger C, Allison BZ, Edlinger G (eds) Brain-computer interface research: a state-of-the-art summary. Springer, Heidelberg, pp $15-23$

43. Novak D (2019) Biomechatronic applications of braincomputer interfaces. In: Segil J (ed) Handbook of biomechatronics. Academic Press, London, pp 129-175

44. Kennedy PR, Adams KD (2003) A decision tree for braincomputer interface devices. IEEE Transactions on Neural Systems and Rehabilitation Engineering 11(2):148-150

45. Moghimi S, Kushki A, Marie Guerguerian A, Chau T (2013) A review of EEG-based brain-computer interfaces as access pathways for individuals with severe disabilities. Assist Technol 25(2):99-110. https://doi.org/10.1080 $/ 10400435.2012 .723298$

46. Thompson MC (2019) Critiquing the concept of BCI illiteracy. Sci Eng Ethics. https://doi.org/10.1007/s11948-0180061

47. Mühl C, Allison B, Nijholt A, Chanel G (2014) A survey of affective brain computer interfaces: principles, state-of-theart, and challenges. Brain-Computer Interfaces 1(2):66-84. https://doi.org/10.1080/2326263X.2014.912881

48. Wu S, Xu X, Shu L, Hu B Estimation of valence of emotion using two frontal EEG channels. In: 2017 IEEE International Conference on Bioinformatics and Biomedicine (BIBM), 13-16 Nov. 2017. pp 1127-1130

49. Douglas M (2001) Purity and danger. An analysis of concepts of pollution and taboo. Routledge, New York

Publisher's Note Springer Nature remains neutral with regard to jurisdictional claims in published maps and institutional affiliations. 